\title{
Lições Aprendidas do Ensino Remoto em uma Disciplina de Engenharia de Requisitos: um Relato de Experiência
}

\author{
João Ricardo dos S. Rosa, Natasha Malveira Costa Valentim \\ Departamento de Informática \\ Universidade Federal do Paraná (UFPR) - Curitiba, PR - Brasil \\ joao.doseufpr.br, natasha@inf.ufpr.br
}

\begin{abstract}
Due to a COVID-19 pandemic, several higher education institutions have adopted Emergency Remote Teaching (ERT). This paper presents an experience report of a Requirements Engineering discipline carried out at ERT in a public university. In this discipline, a methodology was adopted containing synchronous activities, such as expository classes, and asynchronous activities, such as practical work, among other activities. As a result, the lessons learned using this methodology and the students' feedback on their learning and the classes taught are presented. In general, the students were positive, highlighting the teacher's interaction with them in the practical exercises of the synchronous classes.
\end{abstract}

Resumo. Devido a pandemia do COVID-19, várias instituições de ensino superior adotaram o Ensino Remoto Emergencial (ERE). Este artigo apresenta um relato de experiência de uma disciplina de Engenharia de Requisitos realizada no ERE em uma universidade pública. Nesta disciplina adotou-se uma metodologia contendo atividades síncronas, como aulas expositivas, e atividades assíncronas, como trabalhos práticos, dentre outras atividades. Como resultados, são apresentadas as lições aprendidas no uso desta metodologia, além do feedback dos alunos sobre o seu aprendizado e sobre as aulas ministradas. No geral, os alunos foram positivos destacando a interação da professora com eles nos exercícios práticos das aulas síncronas.

\section{Introdução}

Recentemente, a nova pandemia gerada pelo COVID-19 impossibilitou que muitos alunos se encontrassem entre si e com seus professores pessoalmente em uma sala de aula. Muitas instituições acadêmicas foram obrigadas a fazer a transição para um modelo online ou híbrido. Esta realidade não foi diferente para instituições de ensino superior que tiveram que adotar o Ensino Remoto Emergencial (ERE).

Neste contexto pandêmico, a Universidade Federal do Paraná (UFPR) adotou o período especial para o desenvolvimento de atividades de ensino nos cursos de educação superior, profissional e tecnológica, viabilizada através da Resolução $\mathrm{N}^{\mathrm{o}}$ 65/2020-CEPE (2020). Este período especial permitiu que um determinado conjunto de disciplinas e/ou unidades curriculares dos cursos fossem realizados remotamente.

Sabe-se que é importante compartilhar experiências de forma a disseminar lições aprendidas e desafios enfrentados tanto pelos professores quanto pelos alunos durante $o$ ERE. Portanto, este artigo tem o objetivo de apresentar a metodologia utilizada por uma 
professora em uma disciplina de Engenharia de Requisitos (ER) ministrada remotamente nos cursos de Ciência da Computação e Informática Biomédica da UFPR. Segundo Sommerville (2011), os requisitos de um sistema são as descrições do que o sistema deve fazer, os serviços que este oferece e as restrições a seu funcionamento. Esses requisitos refletem as necessidades dos clientes para um sistema que serve a uma determinada finalidade. A ER permite a identificação do contexto de um problema, identificação dos requisitos do cliente dentro desse contexto e entrega de uma especificação que atenda às necessidades do cliente dentro desse contexto.

Para Portugal et al. (2016), a difícil tarefa de projetar uma abordagem para transmitir conceitos de ER deve abranger a experiência prática. $\mathrm{O}$ desafio, em aulas remotas, é justamente possibilitar esta prática. Diante disso, foi proposta aos alunos desta disciplina uma metodologia mais prática, mesmo que remotamente, e que facilmente pode ser adaptada para outras disciplinas. As percepções destes alunos sobre a aprendizagem na disciplina foram analisadas. De maneira geral, os alunos consideraram que seu aprendizado na disciplina foi positivo, destacando-se a importância dos exemplos e exercícios práticos realizados durante as aulas expositivas síncronas e a interação com a professora, além da execução dos trabalhos práticos.

Este artigo está dividido da seguinte maneira: Seção 2 apresenta alguns trabalhos relacionados, Seção 3 apresenta a metodologia na disciplina de ER no contexto de ERE, Seções 4 e 5 apresentam os resultados quantitativos e qualitativos dos feedbacks dos alunos e Seção 6 apresenta as considerações finais e trabalhos futuros.

\section{Trabalhos relacionados}

Nesta seção são apresentados trabalhos que relatem experiências com alunos em uma disciplina de Engenharia de Software (ES) com contexto ER e/ou uma disciplina específica de ER, ambos em contexto remoto. Moster et al. (2021) apontam que devido à pandemia do COVID-19, as universidades foram forçadas a mudar para uma modalidade online ou híbrida rapidamente, obrigando os alunos do Ensino Superior adotarem softwares de comunicação. Dessa forma, os autores apresentam uma proposta com base no ERE sobre avaliação de ferramentas de comunicação usadas por uma equipe de alunos da disciplina de ES, considerando os seguintes aspectos: produtividade da equipe, eficácia da comunicação e sentimentos em relação ao uso de software de comunicação em vez de reuniões pessoais. Os autores concluem que, se prepararmos os alunos durante este período para exercerem funções remotas, eles terão uma vantagem significativa em encontrar carreiras de ES no futuro.

A pesquisa apresentada por Włodarski et al. (2021) investiga como a escolha de abordagens iterativas, sequenciais e híbridas influenciam no sucesso durante $o$ desenvolvimento de projetos para interface web desenvolvidos por novos alunos. Além disso, os autores apresentam um experimento controlado com alunos da disciplina de ES para avaliar os impactos de um determinado método de desenvolvimento no sucesso de empreendimentos de computação dos alunos. Devido a uma duração limitada do projeto, a atividade de ER foi realizada antes do curso por seus instrutores e os alunos receberam um Backlog de histórias de usuários, classificadas de acordo com sua prioridade. A partir da terceira semana das aulas, devido à pandemia do COVID-19, todas as atividades subsequentes foram realizadas remotamente usando o Discord como o principal canal de comunicação. Os autores finalizam afirmando que possibilitar aos 
alunos experiências práticas bem definidas na construção de um sistema de software por meio de atividades de design, implementação, teste e gerenciamento pode ser um excelente meio para a prática no ensino remoto.

Lelli et al. (2020) apresentam uma metodologia baseada no ERE por conta da pandemia do COVID-19. Baseada na gamificação, a metodologia empregada pelos autores foi aplicada em duas disciplinas do curso de Ciência da Computação: ES e Fundamentos de Programação. Para aplicar a gamificação, os autores primeiro organizaram o conteúdo em módulos e, em seguida, definiram quais atividades deveriam ser trabalhadas dentro de cada módulo. Na disciplina de ES, especificamente no módulo 4, apresentou-se os conceitos e técnicas da ER e discutiu-se os principais problemas de elicitação de requisitos. Foi selecionada uma plataforma de gamificação online gratuita que permitiu aos alunos usarem ferramentas assíncronas (fóruns, vídeos) e síncronas (bate-papos) durante as disciplinas. Os resultados deste estudo mostraram que a maioria dos alunos apontou a gamificação como uma experiência positiva para o aprendizado à distância. No entanto, uma parte destes relatou apresentar dificuldades para entender como interagir por meio de ferramentas assíncronas.

Não foi identificado na literatura uma metodologia de ensino que fosse específica para uma disciplina completa de ER. Sendo assim, neste artigo buscou-se apresentar a metodologia adotada em uma disciplina de ER tendo como os principal foco a elicitação, especificação e validação de requisitos, além da realização de trabalhos práticos no contexto ERE. Lições aprendidas são apresentadas juntamente com o feedback dos alunos sobre seu aprendizado e sobre as aulas ministradas.

\section{Metodologia de Ensino}

A disciplina de ER foi conduzida adotando um conjunto de estratégias e de ferramentas de apoio que possibilitaram a flexibilidade da participação do aluno, considerando sua diversidade de condições e de tempo de acesso. Esta disciplina no período remoto teve carga horária de $60 \mathrm{~h}$ dividida em atividades síncronas e assíncronas (Figura 1). As atividades síncronas foram realizadas pela professora e alunos em conjunto. As atividades assíncronas foram realizadas pelos alunos, algumas individualmente e outras em grupo. A disciplina foi organizada em 6 semanas. Durante esse período, os seguintes tópicos foram abordados: introdução à ER ( $1^{\mathrm{a}}$ semana), elicitação de requisitos $\left(2^{\mathrm{a}}\right.$ e $3^{\mathrm{a}}$ semana), especificação de requisitos ( $4^{\mathrm{a}}$ e $5^{\mathrm{a}}$ semana) e validação de requisitos $\left(6^{\mathrm{a}}\right.$ semana). A professora desta disciplina contou com o apoio de um monitor que tinha a função de apoiar na retirada de dúvidas, auxiliar na elaboração de materiais para as aulas e auxiliar na avaliação das atividades realizadas.

$\mathrm{Na} 1^{\text {a }}$ semana, na aula de introdução à disciplina e ao conteúdo de ER, foi solicitado aos alunos que nas semanas seguintes lessem o material complementar (etapa 1 da Figura 1), antes de cada aula expositiva. Esta é uma prática da Sala de Aula Invertida [Bergmann e Sams 2016], onde o aluno é incentivado a auto aprendizagem e onde o professor tem mais tempo para acompanhar e orientar os alunos durante a aula síncrona, seja na resolução de exercícios ou no esclarecimento das dúvidas. Além disso, esta prática possibilita ao aluno aprender no seu próprio ritmo, ou seja, retorne quantas vezes precisar para entender e fazer as suas anotações sobre o conteúdo, e, por conseguinte, permite uma melhor interação entre aluno-professor e aluno-aluno. Os 
materiais complementares como artigos foram disponibilizados pela professora da disciplina por meio do Moodle, além de sugestões de livros, sites e softwares gratuitos.

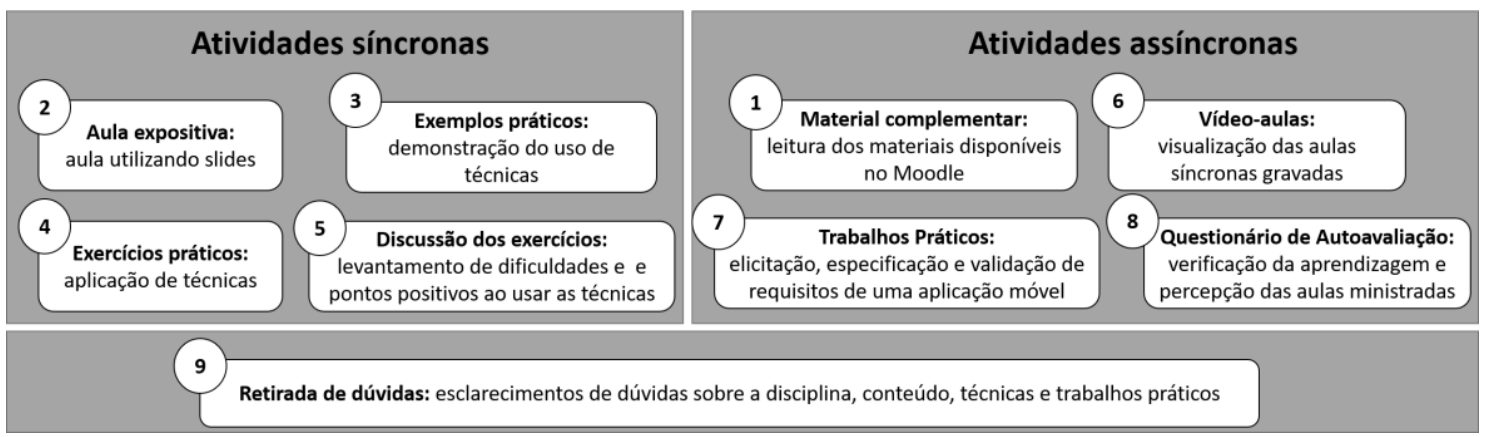

Figura 1. Metodologia de Ensino

Da $2^{\mathrm{a}}$ semana à $6^{\mathrm{a}}$ semana, 5 aulas expositivas síncronas foram realizadas, uma aula a cada semana, com duração de $2 \mathrm{~h}$ cada. Em cada aula expositiva, a professora apresentou o conteúdo utilizando um conjunto de slides (etapa 2 da Figura 1), apresentou exemplos práticos de uso das técnicas de ER (etapa 3 da Figura 1) como Persona e Mapa de Empatia, propôs exercícios práticos para serem feitos em conjunto com todos os alunos (etapa 4 da Figura 1) e fomentou discussões entre os alunos sobre dificuldades e pontos positivos na aplicação das técnicas trabalhadas na disciplina (etapa 5 da Figura 1). As aulas expositivas síncronas foram gravadas, gerando as vídeoaulas (etapa 6 da Figura 1), que foram disponibilizadas no BBB e tinham como intuito garantir acesso ao conteúdo para os alunos que não assistiram a aula expositiva síncrona ou para aqueles que desejassem revê-la para revisar algum conteúdo da disciplina.

Para os trabalhos práticos (etapa 7 da Figura 1), os 30 alunos foram organizados em 15 duplas, onde cada integrante exercia o papel de engenheiro de requisitos e a professora e o monitor da disciplina eram os clientes. A professora solicitou que as duplas identificassem um problema do dia-a-dia que poderia ser resolvido através de uma aplicação móvel. Cada dupla ficou livre para escolher o contexto da sua aplicação. Além disso, caso os alunos apresentassem dúvidas durante a execução das atividades a professora esclarecia as mesmas durante as aulas síncronas. $\mathrm{O}$ objetivo e as atividades de cada trabalho prático são descritos a seguir.

O Trabalho Prático 1 (TP1) teve como objetivo possibilitar ao aluno praticar a elicitação de requisitos de uma aplicação móvel. Este trabalho foi feito em duplas e cada dupla escolheu o tema de sua aplicação móvel. O TP1 possuiu as seguintes atividades: (a) utilizar no mínimo quatro diferentes técnicas de elicitação de requisitos (como Entrevista e Brainstorming) para entender as necessidades do cliente e identificar requisitos de uma aplicação móvel; e (b) entregar um relatório descrevendo (i) como cada técnica auxiliou no processo da elicitação de requisitos, e (ii) os problemas e dificuldades enfrentados pela dupla durante a aplicação de cada técnica. Foi dado o prazo de duas semanas para a realização deste trabalho.

O Trabalho Prático 2 (TP2) teve como objetivo possibilitar a cada dupla praticar a especificação dos requisitos elicitados no TP1. O TP2 conteve as seguintes atividades: (a) descrever os atores da aplicação móvel; (b) criar o diagrama de caso de uso da aplicação; (c) especificar pelo menos quatro dos principais casos de uso da aplicação, 
sendo duas especificações para cada integrante da dupla; e (d) criar um diagrama de atividades. Para a atividade de especificação de caso de uso (c), as duplas deveriam descrever o nome do caso de uso, atores, pré-condições, fluxo principal, alternativo e de exceção, pós-condição, e regras de negócio. Caso as duplas percebessem novos requisitos, elas poderiam adicionar uma seção no relatório do TP2 deixando claro os novos requisitos. Para este trabalho também foi dado o prazo de duas semanas.

O Trabalho Prático 3 (TP3) teve como objetivo possibilitar a cada aluno, individualmente, praticar a validação dos requisitos elicitados no TP1 e especificados no TP2. O TP3 conteve as seguintes atividades: (a) ler e analisar com atenção os requisitos identificados e as especificações dos casos de uso da aplicação móvel definidos pela dupla; e (b) construir individualmente protótipos de baixa fidelidade da aplicação móvel. Para a atividade de prototipação foi solicitado que os alunos (i) representassem nas telas as regras de negócio, mensagens da aplicação e a navegabilidade entre telas, e (ii) qual o requisito e/ou a especificação de caso de uso seguiu como base para a prototipação de cada tela. Foram sugeridos softwares gratuitos de prototipação, como Marvel e Pencil. Para este trabalho foi dado o prazo de uma semana.

Ao final da disciplina foi solicitado que cada aluno respondesse o Questionário de Autoavaliação (etapa 8 da Figura 1) contendo perguntas sobre sua aprendizagem na disciplina e sobre sua percepção das aulas ministradas. As duas perguntas feitas neste questionário serão apresentadas na Seção 4. Dúvidas sobre a disciplina (etapa 9 da Figura 1), sobre seus conteúdos e sobre as suas atividades foram respondidas de modo assíncrono no Moodle pela professora e/ou monitor por meio do recurso de mensagem e fórum de discussão, e de modo síncrono nas aulas expositivas. De maneira geral, o Moodle serviu como repositório de materiais, ambiente de entrega dos resultados das atividades, e ambiente mediador da comunicação entre alunos e professora.

\section{Resultados Quantitativos}

Saber a percepção dos alunos sobre a disciplina é um aspecto importante para entender se o aluno considera que teve sucesso ou não em seu aprendizado. Portanto, duas perguntas foram feitas no Questionário de Autoavaliação com o intuito de saber como o aluno (1) avalia sua aprendizagem e como (2) avaliam as aulas ministradas na disciplina remota. Dos 30 alunos matriculados na disciplina, 27 responderam este questionário.

A $1^{\text {a }}$ pergunta foi "Como você avalia a sua aprendizagem dos conteúdos abordados na disciplina de Engenharia de Requisitos?". Os alunos responderam esta pergunta em uma escala Likert de 5 pontos, sendo as opções Péssimo, Ruim, Muito bom, Bom e Excelente. Para esta pergunta, dos 27 alunos, 16 assinalaram que seu aprendizado foi "Muito Bom"; 3 assinalaram "Bom", e 8 assinalaram "Excelente". Destaca-se que nenhum aluno relatou que seu aprendizado foi "Ruim" ou "Péssimo" na disciplina. Apesar de saber das dificuldades do ERE, pode-se dizer que estes resultados mostram que os alunos consideram seu aprendizado positivo na disciplina.

A $2^{\mathrm{a}}$ pergunta foi "Como você avalia as aulas ministradas na disciplina Engenharia de Requisitos de maneira remota?". Os alunos responderam esta pergunta usando a mesma escala Likert da pergunta anterior. Dos 27 alunos, 13 avaliaram as aulas como "Muito Boa", 3 alunos avaliaram como "Boa", e 11 alunos avaliaram como "Excelente". Também nenhum dos alunos avaliou as aulas ministradas como Ruim ou 
Péssimo. Sendo assim, de maneira geral, a aceitação dos alunos sobre metodologia utilizada durante as aulas da disciplina foi positiva.

\section{Resultados Qualitativos e Discussões}

No Questionário de Autoavaliação foi solicitado que os alunos comentassem ou justificassem suas respostas dadas nas duas perguntas citadas na Seção 4. Estas respostas foram analisadas qualitativamente a partir de um subconjunto das fases do processo de codificação sugeridas por Corbin e Strauss (2014) para o método Grounded Theory (GT): codificação aberta ( $1^{\mathrm{a}}$ fase) e axial ( $2^{\mathrm{a}}$ fase). Para a análise dos dados qualitativos, foram elaborados códigos relacionados ao feedback que os alunos deram no término da disciplina - codificação aberta ( $1^{\mathrm{a}}$ fase). Em seguida, os códigos foram agrupados de acordo com suas propriedades formando conceitos que representam suas categorias e subcategorias. Por fim, os códigos foram relacionados entre si - codificação axial ( $2^{\mathrm{a}}$ fase). Como não se pretende criar uma teoria, a codificação seletiva ( $3^{\mathrm{a}}$ fase do método GT) não foi realizada. As etapas de codificação aberta e axial foram suficientes para saber o que os participantes acharam da disciplina remota de ER. A seguir serão apresentados e discutidos os resultados qualitativos desta análise.

Sobre a dinâmica da disciplina, um dos participantes disse que houve uma boa relação entre prestar atenção nas aulas e o uso de exemplos e exercícios práticos (veja citação do P05). Além disso, outro participante disse que a professora ministrou todas as aulas de forma dinâmica, o que facilitou na realização dos trabalhos práticos (veja citação do P07). Por fim, um outro participante relatou que os materiais complementares disponíveis no Moodle para compreensão melhor do conteúdo da disciplina, em conjunto com as aulas expositivas síncronas e os trabalhos práticos facilitaram seu aprendizado (veja citação do P25). Portanto, um ponto forte da metodologia adotada foi a dinâmica realizada durantes as aulas expositivas síncronas, onde houve uma maior interação dos alunos com a professora. Nesta dinâmica, por exemplo, a professora explicava uma técnica de elicitação, apresentava um exemplo prático, e solicitava aos alunos aplicarem esta técnica a partir de uma situação-problema dada pela professora.

"Houve uma boa mistura de "prestar atenção na explicação" e atividades e dinâmicas nas aulas” (P05);

"Professora aplicou aulas de forma dinâmica, tendo uma constante interação aluno - docente, podendo facilitar a interpretação do trabalho que seria realizado em sequência ao conteúdo apresentado em aula” (P07).

"Com o conjunto aula + textos + trabalhos, foi possível ver teoria e prática ao mesmo tempo, o que facilitou no aprendizado” (P25).

Sobre a didática da professora foram percebidos os seguintes aspectos: interação da professora com os alunos, domínio para ministrar aulas online e explicação clara. Em relação a interação da professora, um dos alunos relatou que a maneira como a professora interagia na disciplina despertava a atenção do aluno (veja a citação de P24). Além disso, um outro participante disse que a professora mantinha constante interação com os alunos e destes com as aulas (veja a citação de P13). Um dos alunos também disse que a professora tem domínio para ministrar aulas online (veja citação P05). Em relação a explicação da professora sobre conteúdo da disciplina, um dos participantes disse que esta foi clara e possibilitou uma boa compreensão ao aluno (veja citação de 
P16). Segundo Dotta et al. (2012), em aulas síncronas, o professor não pode manter apenas uma função de mero apresentador de conteúdo, diferente de aulas que costuma ocupar nas aulas presenciais tradicionais. $\mathrm{O}$ docente deve também criar condições para que se estabeleça um clima amigável entre os alunos e que estes interajam entre si.

"Curti que a professora sempre procurava fazer uma parte interativa, isso "acordava" e fazia você digerir melhor o conteúdo" (P24);

"A professora, mesmo com as dificuldades de uma disciplina ministrada remotamente, conseguiu promover a interação entre os alunos e destes com a aula” (P13);

“A professora demonstra bom domínio de como ministrar aulas online” (P05);

"As explicações sempre foram claras e, com o apoio dos slides, permitiram que a matéria fosse bem compreendida, de maneira que tive uma boa base para aplicar as técnicas expostas." (P16).

Sobre as dificuldades do ensino remoto foram percebidos os seguintes aspectos: tempo para achar um conteúdo falado na aula gravada, tempo corrido para passar o conteúdo da disciplina e distrações na modalidade a distância. Em relação a aulas gravadas um dos participantes disse que teve dificuldade para encontrar um determinado tópico que a professora falou na aula (veja citação do P25). Em relação ao tempo para absorção do conteúdo da disciplina, um dos participantes disse que em alguns momentos tinha dificuldade em compreender o conteúdo, pois a professora tinha que apresentar o conteúdo rápido (veja citação do P24). Em relação a modalidade à distância, um dos participantes relatou que esta modalidade de ensino o distrai mais que a modalidade presencial (veja citação do P12). As dificuldades do ensino remoto identificadas nesta análise vão ao encontro com as dificuldades identificadas por Mohmmed et al. (2020), onde destaca-se prazo curto para projetar a disciplina, falta de foco, ambiente não adequado e dificuldades de acesso à plataforma.

"Por mais que as aulas fiquem gravadas, leva muito tempo pra achar um determinado tópico ou algo que a professora falou, sendo que o conteúdo poderia ser passado mais rápido em aulas gravadas" (P25);

"Achei complicado que em alguns momentos a professora precisava correr com o conteúdo e não dava para pegar nada direito, precisando rever mais tarde" (P24);

"As aulas e o conteúdo foram boas, porém a modalidade a distância não me agrada, me sinto muito mais distraído que em sala” (P12).

Sobre as atividades da disciplina foram destacados os seguintes aspectos: aprendizagem através dos trabalhos práticos, nível equilibrado das atividades da disciplina e o uso de exemplos e exercícios durante as aulas. Em relação aos trabalhos práticos da disciplina um dos participantes disse que conseguiu compreender melhor o conteúdo através dos trabalhos (veja citação do P09). Outro participante mencionou que a parte prática da disciplina o auxiliou compreender melhor a real importância da disciplina e como a mesma o preparou para o mercado de trabalho (veja citação do P01). Segundo Vieira et al. (2017), o uso de atividades práticas promove uma maior interação entre o professor e o aluno e, consequentemente o aprendizado torna-se mais significativo, estimulando melhor a aprendizagem. Em relação ao nível equilibrado das 
atividades, um dos participantes relatou que o nível das atividades não foi muito fácil e nem muito difícil (veja a citação do P18). Sobre os exemplos e exercícios apresentados no decorrer da disciplina, um dos alunos relatou que os exemplos e exercícios das aulas síncronas o auxiliaram a ter um aprendizado maior (veja citação do P02).

"Não me ative muito à teoria, porém consegui aprender tudo sobre o conteúdo durante os trabalhos práticos" (P09);

"A parte prática foi essencial para eu compreender a imensa importância dessa matéria e como ela vai me ajudar a torna-me um profissional mais preparado para o mercado" (P01);

"As atividades propostas no decorrer da disciplina foram equilibradas, sem ser fácil elou dificil demais” (P18);

"Eu acho muito bom quando tem uma aula em que a gente tem um exemplo junto da aula, onde nós temos que pensar, assim parece que o aprendizado é maior e os exercícios do exemplo da cafeteria ajudaram bastante" (P02).

Sobre as aulas gravadas, um dos participantes disse que assistir as aulas gravadas o auxiliou bastante (veja citação do P18). Além disso, outro participante relatou que gostou das aulas gravadas, pois isso o possibilitou assisti-las em um outro momento (veja citação do P15). Por fim, um outro participante relatou que não assistiu nenhuma aula síncrona ao vivo, mas assistindo as aulas gravadas achou que as aulas estavam bastante completas (veja citação do P11). De maneira geral, as aulas gravadas foram importantes para que os alunos pudessem acompanhar a disciplina caso algo o impossibilitasse de assistir a aula síncrona ou desejasse rever um determinado conteúdo.

"As aulas foram extremamente boas. A didática foi excelente e o fator das aulas serem gravadas me auxiliou bastante” (P18).

"Gostei de poder assistir sem ser necessariamente no horário ao vivo, pois assim deixou possivel ver nos horários livres" (P15).

"Infelizmente não participei das aulas ao vivo, mas mesmo assistindo as gravações achei que as aulas foram bastante completas" (P11).

Com relação as aulas síncronas, foi percebida a semelhança das aulas síncronas com as presenciais, a interação entre aluno e professora e duração das aulas. Com relação a comparação das aulas síncronas com as presenciais, um dos alunos citou a semelhança dessas aulas, apesar das limitações da modalidade à distância (veja citação do P19). Além disso, um outro participante relatou que gostou como todo o conteúdo da disciplina foi ministrado em poucas aulas, diferente da forma presencial onde mais aulas são ministradas (veja citação do P08). Isso vai de encontro ao feedback dado pelo P24, apresentado na categoria "Dificuldades do ensino remoto", que relatou dificuldade em compreender o conteúdo apresentado de forma rápida. Diante disso, vale ressaltar que cada aluno possui desenvolvimento diferente de aprendizagem. Alguns alunos precisam de mais tempo para assimilar o conteúdo e isso deve ser levado em consideração no ERE. Adicionalmente, um dos participantes disse que as aulas síncronas permitiram uma constante interação simultânea entre o aluno e professora (veja a citação do P01). Em relação a duração das aulas síncronas um dos participantes disse que o conteúdo poderia ser passado mais rápido e uma aula de dúvidas poderia ser agendada (veja citação do P25). Sendo assim, uma possível adaptação à metodologia utilizada seria o 
acréscimo de uma aula por semana para que os alunos tirem mais dúvidas sobre o conteúdo. Além disso, uma sugestão seria reforçar em cada aula síncrona que os alunos possuem a opção do fórum do Moodle para compartilhar suas dúvidas.

“Apesar da limitação de uma aula no estilo EAD, as aulas foram bem parecidas com as presenciais, incluindo a interação com alunos" (P19).

"As aulas foram bem fluidas e passaram bastante conteúdo em pouco tempo. Achei ótimo tanto conteúdo ser passado em tão poucas aulas comparado com o presencial” (P08).

"As aulas sincronas, diferente das outras matérias que estou fazendo, foram de conteúdo. Isto deu oportunidade para eu tirar dúvidas e interagir com a professora simultaneamente. Esta facilidade garantiu que o conteúdo fosse absorvido corretamente e assim não fosse necessário achar um erro no trabalho, ou durante os estudos, para mandar um e-mail elou esperar até a próxima aula online para pedir ajuda" (P01).

"No quesito qualidade as aulas foram excelentes, porém aulas [síncronas] de 2 horas de maneira online não são boas (...), o conteúdo poderia ser passado mais rápido em aulas gravadas e uma aula de dúvidas poderia ser agendada” (P25).

\section{Conclusões e Trabalhos Futuros}

Este artigo apresentou um relato de experiência no contexto de ERE em uma disciplina de ER. Ao longo desta disciplina utilizou-se uma metodologia baseada em aulas expositivas síncronas e aulas gravadas. Nos encontros síncronos houve explicação de conteúdo, exemplos, exercícios práticos e discussões. As atividades assíncronas envolviam a leitura de artigos e capítulos de livros clássicos da ES, além de materiais extras como sites sobre os conteúdos abordados. Além disso, nas atividades assíncronas os alunos realizaram trabalhos práticos e responderam um questionário de autoavaliação. A metodologia apresentada nesta disciplina pode ser facilmente utilizada em outras disciplinas de ES que exigem uma exposição prática, como teste de software.

Com base na análise qualitativa das respostas fornecidas no questionário de autoavaliação, identificou-se que a execução dos trabalhos práticos foi o elementochave da metodologia adotada, pois contribuiu para o aprendizado dos alunos e os possibilitaram colocar em prática as 3 etapas básicas da ER. Além disso, os alunos reforçaram a importância dos exemplos e exercícios práticos realizados durante as aulas expositivas síncronas, que contribuíram para a retirada de dúvidas sobre o conteúdo. Adicionalmente, alguns feedbacks dados pelos alunos contribuíram com pontos que podem ser melhorados em uma próxima disciplina de ER a ser ministrada durante o período de ERE, como aulas específicas somente para a retirada de dúvidas. Com base na análise quantitativa, identificou-se que a maioria dos alunos avaliou seu aprendizado como "Muito Bom" (16 respostas de 27) e a maioria dos alunos também avaliou as aulas ministradas na disciplina como "Muito Boa" (13 respostas de 27).

A professora da disciplina considerou que, de maneira geral, o conteúdo de ER foi passado e os alunos tiveram experiências práticas positivas. $O$ aprendizado alcançado poderá ajudar os alunos quando estes se encontrarem em projetos de software reais. Porém, a professora considera que se tivesse mais tempo, mesmo que 
remotamente, para aprofundar mais o ensino das técnicas de ER, o aprendizado seria melhor consolidado.

Espera-se que o presente relato ajude outros professores de ER na escolha e definição de atividades a serem realizadas nesta disciplina no formato de ERE. Como trabalhos futuros, pretende-se realizar melhorias na metodologia adotada, de acordo com o feedback dado pelos alunos, a fim de otimizar o aprendizado no ERE.

\section{Referências}

BERGMANN, J; SAMS, A. (2016). Sala de Aula Invertida: uma metodologia de aprendizagem. Rio de Janeiro: LTC.

CORBIN, Juliet; STRAUSS, Anselm. (2014) "Basics of qualitative research: Techniques and procedures for developing grounded theory. Sage publications".

DOTTA, Sílvia; BRAGA, Juliana; PIMENTEL, Edson. (2012). "Condução de aulas síncronas em sistemas de webconferência multimodal e multimídia". In: Brazilian Symposium on Computers in Education (Simpósio Brasileiro de Informática na Educação-SBIE).

LELLI, Valéria et al. (2020). "Gamification in Remote Teaching of SE Courses: Experience Report". In: Proceedings of the 34th Brazilian Symposium on Software Engineering. 2020. p. 844-853.

MOHMMED, Abdalellah O. et al. (2020) "Emergency remote teaching during Coronavirus pandemic: the current trend and future directive at Middle East College Oman”. Innovative Infrastructure Solutions, v. 5, n. 3, p. 1-11.

MOSTER, Makayla; FORD, Denae; RODEGHERO, Paige. (2021). " Is My Mic On?" Preparing SE Students for Collaborative Remote Work and Hybrid Team Communication. arXiv preprint arXiv:2102.01057.

PORTUGAL, Roxana Lisette Quintanilla et al. (2016) "Facing the challenges of teaching requirements engineering". In: 2016 IEEE/ACM 38th International Conference on Software Engineering Companion (ICSE-C). IEEE. p. 461-470.

SOMMERVILLE, I (2011). Engenharia de Software. 9. ed. São Paulo: Pearson Prentice Hall, 529 páginas.

UNIVERSIDADE FEDERAL DO PARANÁ. Conselho Universitário. Resuloção $\mathrm{n}^{\circ}$ 65/2020-CEPE de Outubro de 2020. Disponível em: http://www.soc.ufpr.br/portal/wpcontent/uploads/2020/10/RESOLU\%C3\%87\%C3\%83O-N\%C2\%BA-65-2020CEPE.pdf

VIEIRA-UPE, Alexandre Gomes Teixeira. (2017) "Importância das Atividades Práticas Simples no Ensino de Ciências Naturais: Estudo de Caso em Escola de Lajedo/Pe". Revista Diálogos, n. 17.

WŁODARSKI, Rafał; FALLERI, Jean-Rémy; PARVÉRY, Corinne. (2021). "Assessment of a hybrid software development process for student projects: a controlled experiment”. arXiv preprint arXiv:2103.03534. 